\title{
Ability of Sentence Comprehension according to Syntactic Complexity and Speech Rate in Patients with Dementia of Alzheimer's Type
}

\author{
Hyunjoo Choi \\ Department of Communication Disorders, Korea Nazarene University, Cheonan, Korea
}

Correspondence: Hyunjoo Choi, $\mathrm{PhD}$ Department of Communication Disorders, Korea Nazarene University, 48 Wolbong-ro, Seobuk-gu, Cheonan 31172, Korea

Tel: $+82-41-570-1677$

Fax: +82-41-570-7846

E-mail: hjchoi@kornu.ac.kr

Received: April 4, 2019

Revised: August 10, 2019

Accepted: August 10, 2019

This research was supported by the Korea Nazarene University Research Grants 2019.

\begin{abstract}
Objectives: The ability of sentence comprehension in patients with dementia of Alzheimer's type (DAT) is known to be influenced by syntactic complexity, but the effects of slow speech rate are controversial. The purpose of this study was to investigate the difference of sentence comprehension ability according to the syntactic complexity and slow speech rate in healthy elderly adults and patients with DAT. Methods: Thirty elderly adults and 30 patients with DAT participated in this study. Sentence comprehension ability according to syntactic complexity was evaluated by using a token test, and the speech rate was adjusted to normal speech rate and slow speech rate using the Praat program. Results: First, DAT patients had lower sentence comprehension than elderly adults in both speech rates. Second, as the syntactic complexity increased, the ability to comprehend sentences decreased in both elderly adults and patients with DAT, and this effect was more prominent in patients with DAT. Third, slow speech rate did not improve sentence comprehension ability in both elderly adults and patients with DAT, and slow speech rate in syntactically complex sentences decreased sentence comprehension ability. Conclusion: The results of this study confirmed the characteristics of the deficit the according to the syntactic complexity in patients with DAT, and the effect of sentence comprehension ability due to slow speech rate was different according to syntactic complexity.
\end{abstract}

Keywords: Syntactic complexity, Speech rate, Sentence comprehension, Dementia of Alzheimer's type
알츠하이머형 치매(dementia of Alzheimer's type, DAT) 환자의 의사소통 장애는 인지기능의 손상 정도 및 질환의 중증도(severity) 에 따라 다양한 형태로 나타나며, 이로 인한 의사소통 실패는 보호 자 및 간병인과의 적절한 상호작용을 방해한다(Bayles \& Tomoe$\mathrm{da}, 1991)$. DAT 환자의 다양한 의사소통 문제 중 하나로 청각적인 문장이해 능력의 저하를 들 수 있는데, DAT 환자는 일반 노인에 비 해 청각적 문장이해 능력이 저하되며, 이는 주로 의미적 측면에서의 언어능력 손상이 원인인 것으로 알려져 있다(Grossman \& WhiteDevine, 1998). DAT 환자의 문장이해 능력을 살펴본 연구들은 $\mathrm{DAT}$ 환자의 경우 적어도 질환의 초기에는 능동 문장과 수동 문장 의 이해 능력에 차이가 나타나지 않는 것으로 볼 때 이들의 구문 능
력은 보존되어 있으며, 따라서 이들의 문장이해 결함은 인지적 자 원의 부족 및 의미처리 결함과 관련이 높다고 설명하고 있다 $(\mathrm{Ca}-$ plan \& Waters, 2002; Grossman \& White-Devine, 1998). 이렇듯 $\mathrm{DAT}$ 환자의 문장이해 능력의 제한과 언어의 의미적인 측면의 손 상이 관련 있다는 결과는 대부분의 연구에서 일치하지만 DAT 환 자들의 구문적 능력의 손상 여부와 관련된 연구결과는 혼재한다. 그러나 다음과 같은 이유로 DAT 환자의 구문적 문장이해 능력 또 한 일반노인에 비해 손상됨을 유추할 수 있다. 첫째, DAT 환자들은 단어이해 능력의 손상에 비해 문장이해 능력의 저하가 두드러진다 (Kempler, Almor, Tyler, Andersen, \& MacDonald, 1998). 둘째, 단 어의 친숙도를 통제한 토큰테스트(token test)와 같은 과제 수행에 
서 DAT 환자의 수행이 일반노인에 비해 저하된다(de Jager, Hogervorst, Combrinck, \& Budge, 2003). 마지막으로 DAT 환자의 경우 비가역적 문장이해보다 의미적 해석만으로는 정확히 이해하기 어 려운 가역적 피동문의 이해에서 더 어려움을 보인다(Grober \& Bang, 1995). 즉, 많은 연구결과들은 DAT 환자의 경우 구문 복잡성 이 증가할수록 문장이해 능력의 저하가 뚜렷해지며(Kempler et al., 1998; Small, Andersen, \& Kempler, 1997; Small, Kemper, \& Lyons, 1997; Tomoeda, Bayles, Boone, Kaszniak, \& Slauson, 1990), 이러한 구문 복잡성에 따른 문장이해 수행의 영향은 일반노인에 비해 더 크다고 보고하고 있다(Bickel, Pantel, Eysenbach, \& Schröder, 2000; Kim, Sung, \& Jeong, 2012). 이렇듯 DAT 환자가 구문적으로 복잡 한 문장이해에서 어려움을 보이는 이유는 문장이해를 위한 의미 적, 구문적 언어 능력 이외에 그들의 손상된 작업기억(working memory) 능력과도 관련이 있는 것으로 알려져 있다(MacDonald, Almor, Henderson, Kempler, \& Andersen, 2001; Rochon, Waters, \& Caplan, 1994). 작업기억이란 정보의 저장과 유지, 조작 능력을 동 시에 요구하는 인지기능을 의미하며, 문장이해 시 요구되는 단어기 억을 위한 단기기억, 단어이해, 단어의 연결 및 문장구조의 해석을 위해서 반드시 필요하다(Friedmann \& Gvion, 2003). 작업기억은 일반적인 노화(aging)나 DAT와 같은 질환에 의해 저하되며, 이러 한 작업기억의 손상은 구문적으로 복잡한 문장이해에 더 많은 영 향을 미치는 것으로 알려져 있다(Craik \& Salthouse, 2015).

문장이해에 영향을 미치는 또 다른 요소로 문장을 제시할 때의 말속도를 들 수 있다. 문장이해 능력과 말속도의 관련성을 살펴본 연구들 중 보통보다 빠른 말속도로 문장을 제시하는 것은 청각적 처리를 위한 시간을 부족하게 하기 때문에 문장이해를 방해하는 것으로 알려져 있으며, 이러한 연구결과는 대부분의 연구에서 일치 한다(Gordon-Salant \& Fitzgibbons, 2004). 다음으로 보통보다 느 린 말속도로 문장을 제시했을 때 문장이해에 미치는 영향에 관련 된 연구들도 존재한다. 이와 관련하여 청각장애 성인(Kirk, Pisoni, \& Miyamoto, 1997), 실어증 환자(Friedmann \& Gvion, 2003)를 대 상으로 한 연구에서 보통보다 느린 말속도로 문장을 제시하는 것 이 문장이해 능력을 향상시킨다는 결과들이 보고되고 있다. 그러 나 일반적인 노화(aging) 혹은 인지기능 장애를 가진 대상자의 경 우 보통보다 느린 말속도로 문장을 제시하는 것이 문장이해 능력 을 향상시킨다는 연구들의 결과는 혼재되어 있다. 우선, 일반노인 을 대상으로 한 연구에서 Schmitt와 McCroskey (1981)는 분당 105 단어 정도의 느린 말속도로 문장을 제시했을 경우 분당 175 단어 정 도의 정상 말속도에 비해 문장이해 능력이 다소 향상되었으나, 분 당 35 단어 수준의 아주 느린 말속도로 문장을 제시한 경우에는 문
장이해 능력을 향상시키지 못했다고 보고하였다. 또한 Schmitt와 McCroskey (1981)와 유사한 말속도로 문장을 제시한 Schmitt와 Moore (1989)의 연구에서는 느린 말속도, 아주 느린 말속도 모두에 서 문장이해 능력을 향상시키는 효과는 없었다고 보고하였다. 다 음으로 DAT 환자를 대상으로 한 Tomoeda 등(1990)은 분당 160단 어 수준의 정상 말속도와 분당 120 단어 수준의 느린 말속도에 따른 문장이해 능력의 차이는 발견되지 않았다고 보고하였다. 또한, DAT 환자를 대상으로 문장이해 능력에 대한 느린 말속도의 영향 을 알아본 Small, Anderson 등(1997)은 작업기억 능력이 상대적으 로 잘 보존되어 있는 환자 집단의 경우 느린 말속도가 문장이해 능 력을 향상시켰으나, 작업기억 능력이 손상된 환자 집단의 경우에는 느린 말속도의 영향이 나타나지 않았으며, 작업기억 능력에 심각한 손상을 가진 환자들의 경우 느린 말속도가 오히려 문장이해 능력 을 저하시킨다고 보고하였다. 즉, 느린 말속도로 문장을 제시하는 것은 청각장애나 실어증을 가진 대상자들에게는 효과적일 수 있으 나, 기억능력 손상을 가진 DAT 환자들에게 느린 말속도로 문장을 제시하는 것은 자극을 기억해야 하는 어려움을 가중시킬 수 있다 (Tomoeda et al., 1990).

임상적으로 느린 말속도가 정상 노인이나 인지결함을 가진 노인 들의 문장이해 능력을 높일 것으로 기대하지만, 실험적 데이터는 이러한 결론을 반드시 지지하지는 않는다. 즉, DAT 환자의 경우 많 은 연구들은 보통보다 빠른 말속도가 문장 이해력을 저하시킨다는 데에는 동의하지만, 보통보다 느린 말속도가 문장이해 능력에 긍정 적 영향을 미친다는 데에는 모두 동의하지 않는다. 이렇듯 DAT 환 자의 문장이해 능력에 있어서의 느린 말속도의 영향이 연구결과에 따라 달라지는 이유는 지금까지의 연구에서 느린 말속도로 제시한 문장의 구문 복잡성이 통제되지 않았기 때문인 것으로 생각해 볼 수 있다. 즉, 구문 복잡성에 따라 느린 말속도의 영향이 달라질 수 있음에도 불구하고, 이를 구별하여 평가하지 않았기 때문에 사용 된 문장이해 과제에 따라 연구결과가 다르게 나타났을 가능성이 매우 크다. 따라서 본 연구에서는 일반노인과 DAT 환자들을 대상 으로 다양한 구문 복잡성을 가진 문장들을 보통 말속도와 느린 말 속도로 제시하여 구문 복잡성과 느린 말속도의 영향을 동시에 살 펴보고, 정상적인 노화와 DAT로 인한 문장이해 특성의 차이를 살 펴보는 것을 주된 목적으로 하였다.

\section{연구방법}

\section{연구대상}

연구 대상은 일반노인 30 명과 DAT 환자 30 명 총 60 명으로 하였 
Table 1. Results of age, education level, and K-MMSE score and group comparison

\begin{tabular}{lccc}
\hline & Healthy elderly (A) & DAT (B) & Group comparison \\
\hline Age (yr) & $79.00(3.59)$ & $80.93(6.41)$ & $\mathrm{A}=\mathrm{B}$ \\
Education level (yr) & $4.00(4.34)$ & $3.47(3.42)$ & $\mathrm{A}=\mathrm{B}$ \\
K-MMSE score & $27.26(2.18)$ & $18.30(3.01)$ & $\mathrm{A}>\mathrm{B}$ \\
\hline
\end{tabular}

Values are presented as mean (SD).

DAT = dementia of Alzheimer's type; K-MMSE=Korean version of Mini-Mental State Examination (Kang, 2006).

다. 구체적인 선정 기준은 다음과 같다. 우선, 일반노인은 65 세 이상 으로 한국판 간이정신상태검사(Korean-Mini Mental State Examination, K-MMSE; Kang, 2006)에서 16\%ile 이상이면서, 신경학적 질환이 없다고 보고하고, 노인우울척도(Geriatric Depression Scale, GDS; Jung et al., 1997) 평가 결과 18점 이하로 우울증이 없으며, 과 제를 수행하는 데 요구되는 시청각적 문제가 없는 대상자로 하였 다. 다음으로 DAT 환자는 National Institute of Neurological and Communicative Disorders and Stroke and the Alzheimer's Disease and Related Disorders Association (NINCDS-ADRDA; McKhann et al., 1984)의 진단기준에 따라 신경과나 정신과 전문의로 부터 DAT로 진단받은 환자들로 과제를 수행하는 데 요구되는 시 청각적 문제가 없는 대상자로 선정하였으며, 임상적 치매 척도(Clinical Dementia Rating, CDR; Morris, 1993)의 총점이 3 이상인 중도 의 환자들은 제외하였다.

일반노인과 DAT 환자 집단의 연령, 교육년수 및 K-MMSE 점수 의 평균 및 표준편차와 $t$-검정을 통한 집단 비교 결과를 Table 1 에 제시하였다. 두 집단의 연령 $(t=-1.442, p>.05)$ 및 교육년수 $(t=.529$, $p>.05)$ 의 차이는 통계적으로 유의하지 않았으나, K-MMSE 점수 $(t=13.221, p<.001)$ 는 일반노인이 DAT 환자보다 통계적으로 유의 하게 높았다.

\section{연구과제}

\section{문장이해 과제}

일반노인과 DAT 환자의 문장이해 능력을 평가하기 위하여 본 연구에서는 토큰테스트를 사용하였으며, 토큰테스트의 문항은 Chung, Kim과 Shin (2008)에 의해 개발된 아동용 토큰검사(Token Test for Children-Second Edition, TTFC-2)의 문장에 일부 문 항을 추가하여 사용하였다. 토큰테스트는 검사자가 불러주는 문 장을 듣고 크기(큰, 작은)와 색깔(파랑, 초록, 노란, 하얀, 빨간)이 다 른 모양(동그라미, 네모)을 만지거나 조작하는 과제로 청각적 문장 이해 능력뿐 아니라 대상자의 작업기억 능력 평가에도 유용한 것 으로 알려져 있다(Chung et al., 2008). 또한, 토큰테스트는 DAT 환
자의 청각적 문장이해 능력을 평가하는 데 민감하고 유용하며(Faber-Langendoen et al., 1988; Swihart, Panisset, Becker, Beyer, \& Boiler, 1989), 문장의 길이와 복잡성이 증가해도 문장에서 사용되 는 어휘의 친숙성은 동일하기 때문에 구문 복잡성에 따른 문장이 해 능력을 평가하기에 적절한 것으로 알려져 있다(Tomoeda et al., 1990). TFFC-2는 1-4단원으로 구성되어 있으며, 1 단원에서 4단원 으로 갈수록 구문 복잡성이 증가한다. 그중 1-3단원은 구문 복잡성 에 차이가 없는 각 10 개의 문장으로 구성되어 있으며, 4 단원은 문 장 길이와 구문 복잡성이 점진적으로 증가하는 16 개의 문장을 포 함하고 있다. 본 연구에서는 각 단원별 문장을 보통 말속도와 느린 말속도로 구별하여 들려주는데 문항수의 제한이 있을 것을 고려 하여 1-3단원 문장에 각 6 개의 구조가 동일한 문장을 추가하여 모 든 단원의 문장수가 16 개가 되도록 수정하였다. 각 단원별 문장의 예시를 Appendix 1에 제시하였다. 단원별 토큰테스트의 수행 결과 는 수행률(\%)로 환산하였다.

\section{말속도의 조절}

보통 말속도와 느린 말속도로 문장 제시 속도를 조정하기 위하 여 Praat 음성분석 프로그램 version 6.0.33을 사용하였다. 말속도 의 기준은 최근의 연구결과를 종합하여 결정하였다. 우선 지역, 성 별, 세대별 한국인의 말속도를 조사한 Lee, Shin, Yoo와 Kim (2017) 의 연구에서는 보통 말속도의 평균은 초당 4.82 음절이라고 보고하 였으며, Shin (2018)의 연구에서는 4.76음절로 나타나 두 연구의 결 과가 매우 유사하였다. 본 연구에서는 적절한 말속도로 토큰테스 트의 문장을 녹음한 후 Praat 음성분석 프로그램을 사용하여 보통 말속도는 초당 4.7음절로, 느린 말속도는 선행연구(Schmitt \& McCroskey, 1981)에 따라 문장을 말하는 데 걸린 총 시간을 1.5 배로 연장하여 초당 3.1음절로 조정하여 문장을 제시하였다. 또한, 음향 학적 말속도 조정으로 인한 말소리의 왜곡 및 명료도 문제가 없는 지 판단하기 위하여 언어재활사 국가자격증 소지자로 언어치료학 대학원에 재학 중인 대학원생 20 명이 문장 녹음자료를 평가한 결과 말소리의 왜곡 및 명료도 문제는 전원이 없는 것으로 판단하였다.

\section{연구절차}

본 연구는 나사렛대학교 생명윤리위원회(IRB)의 승인(No. 20191-2) 및 대상자의 서면 동의를 얻어 진행하였다. 모든 과제는 방해를 받지 않는 조용한 방에서 일대일로 수행되었다. 본 검사 이전에 토 큰테스트의 연습문제를 이용하여 연습과제를 실시하였다. 토큰 조 작을 위한 공간을 확보한 상태에서 표준화된 토큰 배열방법에 따라 토큰을 배열한 후 대상자에게 Praat 음성분석 프로그램으로 사전 
에 말속도를 조절하여 배열해 놓은 순서대로 녹음된 문장을 녹음 기를 통하여 들려주었다. 수정된 토큰테스트의 문항 중 각 단원별 홀수 문항은 보통 말속도로, 짝수 문항은 느린 말속도로 제시하였 다. 모든 문장은 1 번씩만 들려주었으며, 대상자의 반응은 즉시 기록 하였다.

\section{통계분석}

IBM SPSS Statistics 22 프로그램을 이용하여 통계분석을 실시하 였으며 우선, 일반노인과 DAT 환자의 구문 복잡성과 말속도에 따 른 문장이해 수행 차이를 알아보기 위하여 집단(2) $\times$ 구문 복잡성 (4) $\times$ 말속도 $(2)$ 의 혼합삼원분산분석을 실시하였다. 또한, 각 집단 별로 구문 복잡성에 따른 차이가 있는지 알아보기 위하여 사후분 석을 실시하였다. 마지막으로 각 집단별로 보통 말속도에서의 문장 이해 총점과 단원별 느린 말속도에서의 문장이해 수행의 상관분석 을실시하였다.

\section{연구결과}

\section{일반노인과 DAT 환자의 구문 복잡성과 말속도에 따른 문장이해 수행률}

일반노인과 DAT 환자의 말속도에 따른 단원별 문장이해 수행률 과 총수행률을 Table 2에 제시하였다. 결과를 살펴보면, 우선 DAT 환자 집단은 일반노인과 비교하여 모든 단원에서 문장이해 능력이 저하됨을 알 수 있다. 또한, 일반노인과 DAT 환자 집단 모두 말속도 와 관계없이 구문 복잡성이 증가할수록 문장이해 수행률이 낮아지 는 것을 알 수 있다. 제시한 문장의 말속도에 따른 차이를 살펴보면, 일반노인의 경우 구문 복잡성이 상대적으로 낮은 1,2 단원에서는 느린 말속도로 문장을 제시했을 때 문장이해 수행률이 미세하게 높아졌으나, 구문 복잡성이 높은 3,4 단원의 경우 느린 말속도로 문
장을 제시했을 때 문장이해 수행률이 오히려 낮아짐을 알 수 있다. 다음으로, DAT 환자의 경우는 구문 복잡성에 관계없이 보통 말속 도로 문장을 제시했을 때보다 느린 말속도로 문장을 제시했을 때 의 수행률이 저하됨을 알 수 있다.

\section{일반노인과 DAT 환자의 구문 복잡성과 말속도에 따른 문장이해 능력의 차이}

일반노인과 DAT 환자의 구문 복잡성과 말속도에 따른 문장이해 의 수행 차이를 알아보기 위하여 혼합삼원분산분석을 실시하였 다. 결과를 살펴보면, 일반노인과 DAT 환자의 집단 차이에 대한 주 효과는 유의한 것으로 나타났다 $(F=2,013.651, p<.001)$. 다음으로 집단 내 주효과를 살펴보면, 구문 복잡성 $(F=245.580, p<.001)$, 말 속도 $(F=7.846, p<.01)$ 모두 유의한 것으로 나타났다. 또한, 상호작

Table 2. Percentage (\%) for performances according to syntactic complexity and speech rate

\begin{tabular}{lcc}
\hline & \multicolumn{2}{c}{ Speech rate (\%) } \\
\cline { 2 - 3 } & \multicolumn{1}{c}{ Normal } & Slow \\
\hline Healthy elderly & $92.78(12.90)$ & $94.43(10.12)$ \\
Section 1 & $91.64(10.55)$ & $93.89(11.98)$ \\
Section 2 & $83.89(16.66)$ & $82.08(18.67)$ \\
Section 3 & $51.67(13.43)$ & $36.67(17.96)$ \\
Section 4 & $80.00(9.04)$ & $76.77(10.10)$ \\
Total & & \\
DAT & $89.44(14.83)$ & $85.56(20.40)$ \\
Section 1 & $80.00(27.47)$ & $76.11(26.14)$ \\
Section 2 & $57.22(26.87)$ & $55.56(24.89)$ \\
Section 3 & $30.42(18.77)$ & $20.00(17.56)$ \\
Section 4 & $64.27(16.67)$ & $59.30(15.88)$ \\
Total &
\end{tabular}

Values are presented as mean (SD). DAT = dementia of Alzheimer's type.
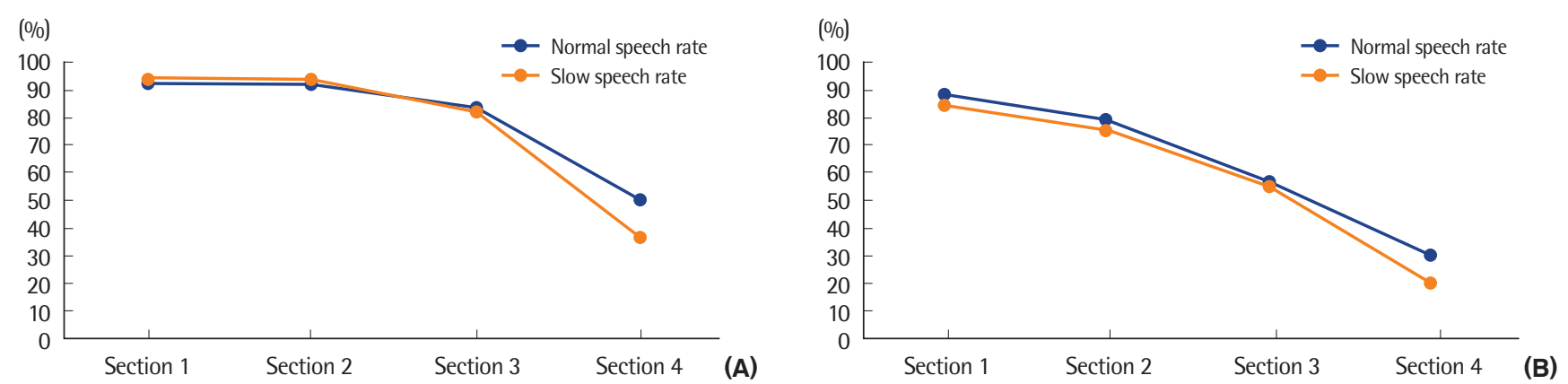

Figure 1. Performances on sentence comprehension according to syntactic complexity and speech rate in (A) healthy elderly group and (B) DAT group. DAT = dementia of Alzheimer's type. 
Table 3. Result of partial correlation among total score of normal speech rate and score of slow speech rate according to section

\begin{tabular}{lcl}
\hline & Healthy elderly & DAT \\
\hline Section 1 & .130 & $.424^{*}$ \\
Section 2 & .193 & $.668^{* * *}$ \\
Section 3 & .344 & $.605^{* * *}$ \\
Section 4 & .064 & $.507^{* *}$ \\
Total & .187 & $.799^{* * *}$ \\
\hline
\end{tabular}

DAT = dementia of Alzheimer's type.

${ }^{*} p<.05,{ }^{* *} p<.01,{ }^{* * *} p<.001$.

용 효과를 분석한 결과 집단과 구문 복잡성 $(F=7.057, p<.001)$, 구 문 복잡성과 말속도 $(F=5.899, p<.001)$ 의 상호작용효과는 유의한 것으로 나타났으나, 집단과 말속도 $(F=.354, p>.05)$, 집단, 구문 복 잡성, 말속도 $(F=1.147, p>.05)$ 의 상호작용효과는 유의하지 않은 것 으로 나타났다. 집단별 구문 복잡성에 대한 사후분석 결과 일반노 인 집단은 1 단원과 2 단원 간의 차이는 유의하지 않았으나, 1 단원과 3,4 단원, 2 단원과 3,4 단원, 3 단원과 4 단원의 차이는 모두 유의한 것 으로 나타났고, DAT 환자의 경우는 모든 단원의 차이가 유의하게 나타났다. 각 집단의 단원별 수행률(\%)을 Figure 1에 제시하였다.

\section{일반노인과 DAT 환자의 말속도에 따른 문장이해 능력의 상관}

일반노인과 DAT 환자의 말속도에 따른 문장이해 능력의 상관을 알아보기 위하여 각 집단별로 보통 말속도에서의 문장이해 수행률 의 총점과 단원별 느린 말속도에서의 문장이해 수행 사이의 상관 분석을 실시하고 그 결과를 Table 3에 제시하였다. 결과를 살펴보 면 일반노인의 보통 말속도에서의 문장이해 능력은 단원별 느린 말 속도에서의 문장이해 수행과 유의한 상관이 나타나지 않은 것에 반해, DAT 환자 집단의 경우 보통 말속도에서의 문장이해 수행률 과 단원별 느린 말속도에서의 문장이해 수행 사이에는 모두 유의한 정적상관이 나타났다.

\section{논의 및 결론}

$\mathrm{DAT}$ 환자의 문장이해 능력에 영향을 미치는 요인을 분석하는 일은 그들과의 의사소통을 원활히 하고 상호작용을 증진시킨다는 측면에서 임상적으로 대단히 중요하다. 이와 관련된 연구들에 따르 면 구문 복잡성, 말속도 등의 변수들이 DAT 환자들의 문장이해 능 력에 영향을 미치는 것으로 보고하고 있으나 이러한 영향에 대한 연구결과들은 혼재되어 있다. 따라서 본 연구에서는 일반노인과 $\mathrm{DAT}$ 환자들을 대상으로 다양한 구문 복잡성을 가진 문장들을 보 통 말속도와 느린 말속도로 제시하여 구문 복잡성과 느린 말속도
의 영향을 동시에 살펴봄으로써 정상적인 노화와 DAT로 인한 문 장이해 특성을 파악하는 것을 주된 목적으로 하였다.

본 연구의 결과를 종합하면, 첫째, DAT 환자 집단은 일반노인과 비교하여 구문 복잡성과 관계없이 문장이해 능력이 저하됨을 알 수 있다. 이러한 결과는 본 연구에서 사용한 토큰테스트 과제에서 사용된 어휘가 크기, 색깔, 모양의 친숙한 어휘인 점을 감안할 때 (Kim, Kim, \& Lee, 2004), 일반노인과 DAT 환자의 문장이해 수행 의 차이는 의미적인 측면이 아닌 구문적인 능력에서의 차이인 것으 로 생각할 수 있다. 또한, 일반노인과 DAT 환자 집단 모두 제시된 말속도와 관계없이 구문 복잡성이 증가할수록 문장이해 수행률이 낮아져, 두 집단 모두 구문 복잡성 증가에 따른 문장이해 능력의 저 하가 확인되었다. 이러한 구문 복잡성의 증가에 따른 문장이해 능 력의 저하는 기존의 연구에서와 같이 작업기억 능력과의 관련성으 로 설명할 수 있다(MacDonald et al., 2001; Rochon et al., 1994). 또 한, 구문적으로 복잡한 문장이해 능력의 손상과 작업기억의 저하 와의 관련성은 일반적인 노화와 DAT로 인한 인지기능 장애 모두 에서 나타남을 알 수 있다.

다음으로 일반노인과 DAT 환자의 말속도에 따른 차이도 모두 유의한 것으로 나타났다. 이는 구문 복잡성에 따라 결과가 다르지 만 구문적으로 상당히 복잡한 문장을 포함한 본 연구 과제의 경우 일반노인과 DAT 환자 모두 느린 말속도에서 문장이해 능력이 저하 됨을 의미한다. 제시한 문장의 말속도에 따른 집단에서의 차이를 살펴보면, 일반노인의 경우 구문 복잡성이 상대적으로 낮은 1,2 단 원에서는 느린 말속도로 문장을 제시했을 때 통계적으로 유의하지 는 않았으나 문장이해 수행률이 미세하게 높아지는 경향을 보였으 며, 구문 복잡성이 가장 높은 4단원의 경우 느린 말속도로 문장을 제시했을 때 문장이해 수행률이 오히려 낮아짐을 알 수 있다. 다음 으로, DAT 환자의 경우는 구문 복잡성에 관계없이 보통 말속도로 문장을 제시했을 때보다 느린 말속도로 문장을 제시했을 때의 수 행률이 저하되었으며, 이러한 수행률의 저하는 구문적으로 가장 복잡한 문장을 포함하고 있는 4단원에서 현저하게 나타났다. 지금 까지 DAT 환자들의 문장이해 능력에 느린 말속도가 미치는 영향 에 대한 연구결과들은 모두 일치하지 않는데, 그 이유는 사용된 문 장의 구문 복잡성의 정도 차이 및 연구 대상자의 작업기억 및 인지 기능의 차이 때문인 것으로 생각해 볼 수 있다. 본 연구에서도 연구 대상자나 제시된 문장의 구문 복잡성에 따라 문장이해 수행에 느 린 말속도가 미치는 영향이 다르게 나타났다. 이러한 결과는 느린 말속도로 문장을 제시하는 것은 정보처리 속도의 저하를 가진 환 자의 문장이해에는 유리하며, 작업기억의 손상을 가진 대상자들에 게는 불리하게 작용한다는 Small, Andersen 등(1997)의 연구결과 
와 연결지어 생각해 볼 수 있다. 본 연구에서 일반노인의 경우 높은 수준의 작업기억을 요구하지 않는 1,2 단원에서는 정상적인 노화로 인한작업기억 저하의 영향이 적어 느린 말속도가 문장이해에 어느 정도 긍정적인 영향을 미친 반면, 구문 복잡성이 증가하여 작업기 억의 영향이 커지면 느린 말속도의 효과가 사라지거나 오히려 문장 이해에 부정적인 영향을 미치는 것으로 나타났다. 이와는 달리 DAT 환자의 경우 정상적인 노화에 비해서도 작업기억 능력이 현저 히 제한되기 때문에 상대적으로 구문 복잡성이 낮은 문장이해에서 도 느린 말속도로 인한 효과를 기대하기 어려웠다. 이러한 결과는 DAT 환자에게 느린 말속도로 문장을 제시하는 것은 정보처리 속 도 제한을 보완하는 유리함보다는 작업기억 손상으로 인한 부정적 인 효과가 크게작용함을 시사한다.

일반노인과 DAT 집단, 구문 복잡성과 말속도의 상호작용효과를 살펴보면, 집단과 구문 복잡성, 구문 복잡성과 말속도의 상호작용 효과가 유의한 것으로 나타났다. 그중 집단과 구문 복잡성의 상호 작용효과는 일반노인의 경우 1-3단원에 비해 4단원의 수행이 급격 히 저하된 것과 달리 DAT 환자의 경우는 1-4단원의 수행이 단계적 으로 저하된 결과를 반영한 것으로 여겨진다. 이러한 상호작용효 과는 집단별 구문 복잡성에 대한 사후분석 결과로도 설명되는데, 사후분석 결과 일반노인 집단은 1 단원과 2 단원 간의 차이는 유의 하지 않았으나, 1 단원과 3,4 단원, 2 단원과 3,4 단원, 3 단원과 4 단원 의 차이는 모두 유의한 것으로 나타났고, DAT 환자 집단의 경우는 모든 단원의 차이가 유의하게 나타났다. 즉, 일반노인의 경우 문장 이해에 문장의 길이 자체보다는 구문 복잡성에 영향을 더 받는 것 에 비해 DAT 환자들은 문장 길이와 구문 복잡성 모두에 영향을 받 음을 알 수 있다. 이러한 결과는 DAT 환자의 문장이해 수행은 구 문 복잡성뿐 아니라 문장 길이에 의한 영향도 나타나며, 이는 DAT 로 인한 단기기억의 저하와 관련이 높다는 기존의 연구결과(Tomoeda et al., 1990)와 맥락을 같이한다. 또한, 구문적으로 단순한 1-2단원의 경우 일반노인과 DAT 환자 사이의 수행 차이가 작은 반 면, 문장 길이가 길고, 구문적으로 복잡한 3-4단원에서 집단 간 차 이가 현저히 큰 것 역시 집단과 구문 복잡성의 상호작용효과로 나 타났음을 유추할 수 있다. 이와 관련하여 DAT 환자는 질환의 초기 에는 문장이해 능력에 구문 복잡성이 미치는 영향이 작으며, 병의 진행에 따라 구문 복잡성의 영향이 커지는 것으로 알려져 있는데, Bickel 등(2000)은 MMSE 점수가 20점 이상인 경도의 DAT 환자의 경우 상대적으로 간단한 문장을 이해하는 구문 능력은 보존되어 있다고 하였다. 본 연구의 DAT 대상자는 K-MMSE 점수 평균이 18 점 정도로 중증의 환자들은 포함되지 않았는데, 이들의 경우 1 단원 처럼 구문적으로 간단한 문장의 이해는 $90 \%$ 정도의 높은 수행률
을 보여, Bickel 등(2000)의 연구결과를 지지한다. 다음으로 구문 복잡성과 말속도의 상호작용효과는 구문적으로 단순한 문장과 구 문적으로 복잡한 문장에서 느린 말속도의 영향이 서로 다르게 나 타난 결과를 반영한 것으로 이러한 영향은 일반노인, DAT 환자 모 두에서 동일하게 나타났다.

마지막으로 일반노인과 DAT 환자의 말속도에 따른 문장이해 능 력의 상관을 알아보기 위하여 각 집단별로 보통 말속도에서의 문 장이해 수행률 총점과 단원별 느린 말속도에서의 문장이해 수행 사이의 상관분석을 실시한 결과 일반노인의 경우 보통 말속도에서 의 문장이해 능력은 단원별 느린 말속도에서의 문장이해 수행과 유의한 상관이 나타나지 않은 것에 반해, DAT 환자 집단의 경우 보 통 말속도에서의 문장이해 수행률과 단원별 느린 말속도에서의 문 장이해 수행 사이에는 모두 유의한 정적상관이 나타났다. 토큰테 스트는 구문 복잡성에 따른 문장이해 능력을 살펴봄과 동시에작업 기억 능력을 평가하는 데 유용한 검사로 알려져 있다(Cohen-Mimran \& Sapir, 2007; Chung et al., 2008). 이러한 결과는 작업기억 능 력이 높을수록 느린 말속도에서의 문장이해 수행이 높음을 의미 하며, 이러한 관련성은 작업기억의 병리적인 손상을 가진 DAT 환 자에게서 뚜렷하게 나타남을 알 수 있다. 또한, 이러한 관련성은 유 사한 진행 정도를 가진 DAT 환자일지라도 환자 개인의 언어나 작 업기억 능력에는 차이가 있을 수 있으므로(Bayles, Tomoeda, \&

Trosset, 1992; Kempler, Andersen, \& Henderson, 1995), 문장이해 능력 향상을 위한 구문 복잡성과 말속도의 조절에서 DAT 환자 집 단 내의 개인차 역시 고려되어야함을 시사한다.

DAT 환자의 언어이해 능력 손상으로 인한 의사소통 실패는 가 족과 간병인의 스트레스로 작용한다(Orange \& Colton-Hudson, 1998). 이러한 문제를 해결하기 위하여 DAT 환자와의 의사소통 상 황에서 적절한 상호작용을 향상시키는 방법을 소개하고 있는 매뉴 얼들은 간단한 문장을 사용하고 천천히 말할 것을 권고한다(Santo Pietro \& Ostuni, 2003; Small, Kemper, et al., 1997). 그중 간단한 문 장을 사용하는 전략은 DAT 환자의 작업기억 용량 제한을 고려하 여 낮은 작업기억 능력으로도 저장과 처리가 가능한 짧고, 구문적 으로 단순한 문장을 사용하도록 하는 것이며, 천천히 말하기 전략 은 DAT 환자의 정보처리 속도의 저하를 고려하여 정보처리에 추 가적인 시간을 제공하는 역할을 할 수 있다. 본 연구에서는 일반노 인과 DAT 환자를 대상으로 다양한 구문 복잡성을 가진 문장을 사 용하여 느린 말속도가 문장이해에 미치는 영향을 알아보았다. 그 결과 말속도와 관계없이 구문 복잡성이 문장이해에 상당히 영향을 미치기 때문에 DAT 환자에게 가급적 단순한 문장을 사용하는 전 략은 매우 유용함을 증명하였다. 그러나 느린 말속도로 문장을 제 
시하는 것은 구문적으로 상당히 간단한 문장의 이해에도 효과적 이지 못했으며, 문장 길이가 길고 구문적으로 복잡한 경우 느린 말 속도는 문장이해에 오히려 부정적인 영향을 미쳤다. 따라서 본 연 구의 결과를 바탕으로 DAT 환자의 문장이해 능력을 향상시키기 위해서는 무엇보다 단순한 문장을 사용하는 것이 최우선이며, 천 천히 말하는 전략은 큰 도움이 되지 않는다는 결론을 내릴 수 있다. 다만, 본 연구에서 문장의 구문 복잡성의 차이를 보다 다양하게 살 펴보지 못한 점, DAT 환자의 중증도에 따른 차이를 비교하지 못한 점이 아쉬움으로 남는다. 앞으로는 이러한 점을 보완하여 DAT 환 자의 다양한 문장이해의 특성과 문장이해 능력에 영향을 미치는 변수에 대한 연구가 활발히 진행되기를 바란다.

\section{REFERENCES}

Bayles, K. A., \& Tomoeda, C. K. (1991). Caregiver report of prevalence and appearance order of linguistic symptoms in Alzheimer's patients. The Gerontologist, 31(2), 210-216.

Bayles, K. A., Tomoeda, C. K., \& Trosset, M. W. (1992). Relation of linguistic communication abilities of Alzheimer's patients to stage of disease. Brain and Language, 42(4), 454-472.

Bickel, C., Pantel, J., Eysenbach, K., \& Schröder, J. (2000). Syntactic comprehension deficits in Alzheimer's disease. Brain and Language, 71(3), 432 448.

Caplan, D., \& Waters, G. (2002). Sentence comprehension in Alzheimer's disease. In: L. T. Connor and L. K. Obler (Eds.), Neurobehavior of Language and Cognition (pp. 61-76). Boston, MA: Springer.

Chung, B. J., Kim, Y. T., \& Shin, M. J. (2008). A pilot study on the development of the Korean-Token Test for Children. Korean Journal of Communication \& Disorders, 13(4), 621-634.

Cohen-Mimran, R., \& Sapir, S. (2007). Deficits in working memory in young adults with reading disabilities. Journal of Communication Disorders, 40(2), 168-183.

Craik, F. I., \& Salthouse, T. A. (2015). The handbook of aging and cognition (3rd ed.). New York, NY: Psychology Press.

de Jager, C. A., Hogervorst, E., Combrinck, M., \& Budge, M. M. (2003). Sensitivity and specificity of neuropsychological tests for mild cognitive impairment, vascular cognitive impairment and Alzheimer's disease. Psychological Medicine, 33(6), 1039-1050.

Faber-Langendoen, K., Morris, J. C., Knesevich, J. W., LaBarge, E., Miller, J. P., \& Berg, L. (1988). Aphasia in senile dementia of the Alzheimer type. An- nals of Neurology, 23(4), 365-370.

Friedmann, N., \& Gvion, A. (2003). Sentence comprehension and working memory limitation in aphasia: a dissociation between semantic-syntactic and phonological reactivation. Brain and Language, 86(1), 23-39.

Gordon-Salant, S., \& Fitzgibbons, P. J. (2004). Effects of stimulus and noise rate variability on speech perception by younger and older adults. The Journal of the Acoustical Society of America, 115(4), 1808-1817.

Grober, E., \& Bang, S. (1995). Sentence comprehension in Alzheimer's disease. Developmental Neuropsychology, 11(1), 95-107.

Grossman, M., \& White-Devine, T. (1998). Sentence comprehension in Alzheimer's disease. Brain and Language, 62(2), 186-201.

Jung, I. K., Kwak, D. I., Shin, D. K., Lee, M. S., Lee, H. S., \& Kim, J. Y. (1997). A reliability and validity study of geriatric depression scale. Journal of Korean Neuropsychiatric Association, 36(1), 103-112.

Kang, Y. (2006). A normative study of the Korean-Mini Mental State Examination (K-MMSE) in the elderly. Korean Journal of Psychology: General, 25(2), 1-12.

Kempler, D., Almor, A., Tyler, L. K., Andersen, E. S., \& MacDonald, M. C. (1998). Sentence comprehension deficits in Alzheimer's disease: a comparison of off-line vs. on-line sentence processing. Brain and Language, 64(3), 297-316.

Kempler, D., Andersen, E. S., \& Henderson, V. W. (1995). Linguistic and attentional contributions to anomia in Alzheimer's disease. Neuropsychiatry, Neuropsychology, \& Behavioral Neurology, 8(1), 33-37.

Kim, J. K., Sung, J. E., \& Jeong, J. H. (2012). Effects of syntactic complexity on sentence comprehension in persons with mild cognitive impairment and dementia of Alzheimer's type. Korean Journal of Communication \& Disorders, $17(2), 338-355$.

Kim, S. J., Kim, J. Y., \& Lee, H. R. (2004). Working memory and language disorders: literature review. Marsori, 51, 39-55.

Kirk, K. I., Pisoni, D. B., \& Miyamoto, R. C. (1997). Effects of stimulus variability on speech perception in listeners with hearing impairment. Journal of Speech, Language, and Hearing Research, 40(6), 1395-1405.

Lee, N., Shin, J., Yoo, D., \& Kim, K. (2017). Speech rate in Korean across region, gender and generation. Phonetics and Speech Sciences, 9(1), 27-39.

MacDonald, M. C., Almor, A., Henderson, V. W., Kempler, D., \& Andersen, E. S. (2001). Assessing working memory and language comprehension in Alzheimer's disease. Brain and Language, 78(1), 17-42.

McKhann, G., Drachman, D., Folstein, M., Katzman, R., Price, D., \& Stadlan, E. M. (1984). Clinical diagnosis of Alzheimer's disease: report of the NINCDS- 
ADRDA Work Group under the auspices of Department of Health and Human Services Task Force on Alzheimer's Disease. Neurology, 34(7), 939944.

Morris, J. C. (1993). The Clinical Dementia Rating (CDR): current version and scoring rules. Neurology, 43(11), 2412-2414.

Orange, J. B., \& Colton-Hudson, A. (1998). Enhancing communication in dementia of the Alzheimer's type. Topics in Geriatric Rehabilitation, 14(2), 56-75.

Rochon, E., Waters, G. S., \& Caplan, D. (1994). Sentence comprehension in patients with Alzheimer's disease. Brain and Language, 46(2), 329-349.

Santo Pietro, M. J. C., \& Ostuni, E. (2003). Successful communication with persons with Alzheimer's disease: an in-service manual (2nd ed.). St. Louis, MO: Butterworth-Heinemann.

Schmitt, J. F., \& McCroskey, R. L. (1981). Sentence comprehension in elderly listeners: the factor of rate. Journal of Gerontology, 36(4), 441-445.

Schmitt, J. F., \& Moore, J. R. (1989). Natural alteration of speaking rate: the effect on passage comprehension by listeners over 75 years of age. Journal of Speech, Language, and Hearing Research, 32(2), 445-450.

Shin, J. (2018). Breath and memory in speech based on quantitative analysis of breath groups and pause units in Korean. Korean Linguistics, 79, 91-116. Small, J. A., Andersen, E. S., \& Kempler, D. (1997). Effects of working memory capacity on understanding rate-altered speech. Aging, Neuropsychology, and Cognition, 4(2), 126-139.

Small, J. A., Kemper, S., \& Lyons, K. (1997). Sentence comprehension in Alzheimer's disease: Effects of grammatical complexity, speech rate, and repetition. Psychology and Aging, 12(1), 3-11.

Swihart, A. A., Panisset, M., Becker, J. T., Beyer, J. R., \& Boiler, F. (1989). The Token Test: validity and diagnostic power in Alzheimer's disease. Developmental Neuropsychology, 5(1), 69-78.

Tomoeda, C. K., Bayles, K. A., Boone, D. R., Kaszniak, A. W., \& Slauson, T. J. (1990). Speech rate and syntactic complexity effects on the auditory comprehension of Alzheimer patients. Journal of Communication Disorders, 23(2), 151-161. 
Appendix 1. 토큰테스트의 단원별 문장의 예시

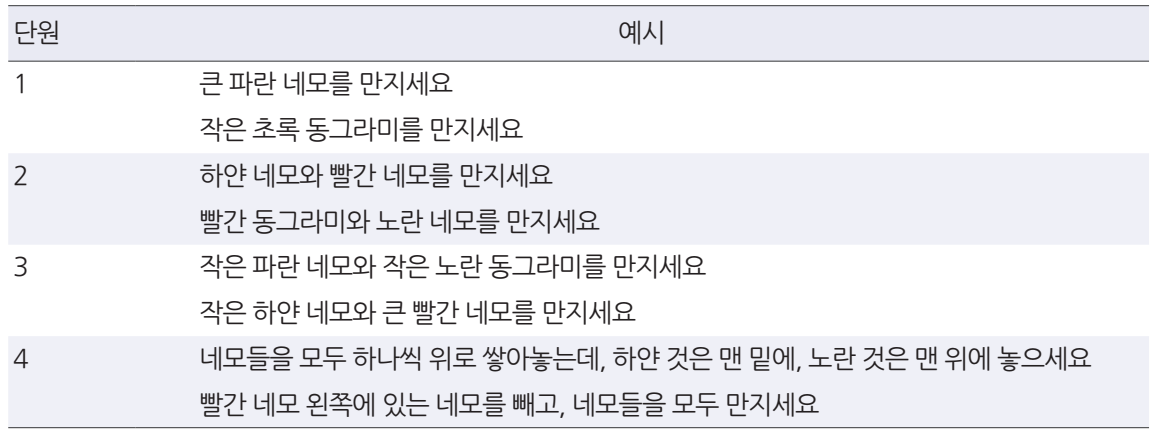




\section{국문초록}

\section{구문 복잡성과 말속도에 따른 알츠하이머형 치매 환자의 문장이해 능력 최현주}

나사렛대학교 언어치료학과

배경 및 목적: 알츠하이머형 치매 환자의 문장이해 능력은 구문 복잡성에 영향을 받는 것으로 알려져 있으나, 느린 말속도에 의한 영향 은 논쟁적이다. 본 연구는 알츠하이머형 치매 환자와 일반노인을 대상으로 구문 복잡성과 말속도에 따른 문장이해 수행 차이를 동시에 알아보는 것을 목적으로 하였다. 방법: 알츠하이머형 치매 환자 30 명과 일반노인 30 명이 본 연구에 참여하였다. 구문 복잡성에 따른 문 장이해 능력은 토큰테스트를 사용하여 평가하였으며, 말속도는 Praat 프로그램을 이용하여 보통 말속도와 느린 말속도로 조정하였다. 결과: 첫째, 말속도와 관계없이 알츠하이머형 치매 환자 집단은 일반노인 집단에 비해 문장이해 능력이 저하되어 있었다. 둘째, 일반노 인, 알츠하이머형 치매 환자 집단 모두 구문 복잡성이 증가할수록 문장이해 능력이 저하되었으며, 이러한 효과는 알츠하이머형 치매 환 자에게서 더 두드러지게 나타났다. 셋째, 느린 말속도는 일반노인, 알츠하이머형 치매 환자 모두 문장이해 능력을 향상시키지 못했으며, 구문적으로 복잡한 문장에서의 느린 말속도는 문장이해 수행을 오히려 저하시켰다. 논의 및 결론: 이러한 연구결과를 통하여 알츠하 이머형 치매 환자의 구문 복잡성에 따른 문장이해 능력의 저하 특성을 확인하였으며, 느린 말속도에 따른 문장이해 능력의 변화는 구 문 복잡성에 따라 달라짐을 알 수 있다.

핵심어: 구문 복잡성, 말 속도, 문장이해, 알츠하이머형 치매

본 연구는 2019년도 나사렛대학교 교내연구비 지원으로 연구되었음.

\section{참고문헌}

강연욱(2006). K-MMSE (Korean-Mini Mental State Examination)의 노인 규준 연구. 한국심리학회지: 일반, 25(2), 1-12.

김수진, 김정연, 이혜란(2004). 작업기억과 언어발달장애: 문헌연구. 말소리, 51, 39-55.

김진경, 성지은, 정지향(2012). 통사적 복잡성에 따른 경도인지장애 환자와 알츠하이머성 치매환자의 문장이해능력 비교. 언어청각장애연구, 17(2),

338-355.

신지영(2018). 언어수행에서의 호흡과 기억. 한국어학, 79, 91-116.

이나라, 신지영, 유도영, 김경화(2017). 한국어 발화 속도의 지역, 성별, 세대에 따른 특징 연구. 말소리와음성과학, 9(1), 27-39.

정부자, 김영태, 신문자(2008). 아동용 토큰 검사의 국내적용 타당화 기초연구. 언어청각장애연구, 13(4), 621-634.

정인과, 곽동일, 신동균, 이민수, 이현수, 김진영(1997). 노인우울척도(Geriatric Depression Scale)의 신뢰도, 타당도 연구. 신경정신의학, 36(1), 103-112.

\section{ORCID}

최현주(https://orcid.org/0000-0003-4654-3206) 